\title{
Effect of the hydroalcoholic extract of pistachio on avoidance learning in male Wistar rats
}

Salari E, BSc ${ }^{1}$, Baloochi M, BSc ${ }^{1}$, Shamsizadeh A, $\mathrm{PhD}^{2 *}$, Ayoobi F, MSc ${ }^{3}$, Allahtavakoli M, $\mathrm{PhD}^{2}$, Taghavi Y, MD ${ }^{4}$, Ravari A, $\mathrm{PhD}^{5}$

1. MSc Student, Dept. of Physiology-Pharmacology, Rafsanjan University of Medical Sciences, Rafsanjan, Iran. 2. Associate Prof., Physiology-Pharmacology Research Centre, Rafsanjan University of Medical Sciences, Rafsanjan, Iran. 3. PhD Student, Dept. of Physiology-Pharmacology, Rafsanjan University of Medical Sciences, Rafsanjan, Iran. 4. Assistant Prof., PhysiologyPharmacology Research Centre, Rafsanjan University of Medical Sciences, Rafsanjan, Iran. 5. Assistant Prof., Geriatric Care Research Center, Rafsanjan University of Medical Sciences, Rafsanjan, Iran

Abstract

Received: December 2015, Accepted: January 2016

Background: Pistachio is a plant that has long been cultivated in different parts of Iran. Pistachios are very nutritious and contain vitamins $\mathrm{E}$ and $\mathrm{B}$, flavonoids, antioxidants, and carotenoids. Since the pistachio is effective in the treatment of some neurological disorders and is indigenous to Iran and considering the substantial use of this nut, it is necessary to investigate its effects on cognitive functions of the brain. This study aimed to investigate the effect of the hydroalcoholic extract of the pistachio on avoidance learning in rats.

Materials and Methods: In this experimental study, 40 male Wistar rats (200-250 g body weight and 2-3 months of age) were divided into 4 groups. Dimethyl sulfoxide (DMSO) $2.5 \%$ (vehicle) and hydroalcoholic extract of the pistachio $(10,50$, and $100 \mathrm{mg} / \mathrm{kg} /$ day) were administered by gavage for 14 days. Avoidance learning test was performed using the shuttle box.

Results: The results of this study indicated a significant increase in the latency to enter the dark room in the groups receiving different doses of pistachio extract compared to vehicle treated group. Moreover, in the treated groups, time spent in the dark room was decreased compared to the vehicle group. The comparison of different doses of pistachio extract demonstrated that $100 \mathrm{mg} / \mathrm{kg}$ was more effective than 10 and $50 \mathrm{mg} / \mathrm{kg}$ of the extract.

Conclusions: The results of this study indicated that treatment of rats with pistachio extract, which is rich in vitamins, flavonoids, and antioxidant compounds, can improve learning and memory.

Keywords: Pistachio, Avoidance Learning, Rat

\section{Introduction}

Since ancient times, herbs have played a significant role in the treatment of many diseases. According to ancient documents, Iranians are pioneers in the use of herbs for medical purposes. Pistachio is a medicinal herb that records of its consumption as a food date back to $7000 \mathrm{BC}$ (1). Pistachio is a genus of the Anacardiaceae family. There are 15 known species of pistachio, but only some species are found in Iran $(1,2)$. Only 3 species of pistachio naturally grow in Iran; P. vera L., P. khinjuk Stocks, and P. atlantica Desf (3). P. vera is the only species used for ${ }^{*}$ commercial cultivation,

\footnotetext{
* Corresponding author: Ali Shamsizedeh, Physiologypharmacology Research Centre, Rafsanjan University of Medical Sciences, Rafsanjan, Iran.

Email: ashamsi@ rums.ac.ir or alishamsy@gmail.com
} 
and the other species are often used as rootstock for P. vera $(3,4)$.

The pistachio fruit or nut is the edible part of the pistachio plant and is used as flavoring in food and snacks and has been used for therapeutic purposes. Pistachios have a warm and dry nature and contain a large amount of plant protein, starch, unsaturated fats, vitamins, fiber, and minerals such as potassium and magnesium (5$8)$. The pistachio is very nutritious and contains vitamins B1, B2, B6, E, and C, calcium, and iron and is effective in boosting physical strength and activity of brain cells $(9,10)$. Other nutrients found in pistachios consist of carotenoids, phenolic compounds such as phenolic acids, flavonoids and other types of polyphenolic compounds, and resveratrol (10). Different parts of the pistachio plant (such as resins, leaves, fruit, and aerial parts) have been investigated for pharmaceutical activities and have traditionally been used for a wide range of purposes (11).

In folk medicine, pistachios have been used in the treatment of eczema, throat infections, kidney stones, and asthma. Furthermore, it is used as an astringent, anti-inflammatory, antipyretic, anti-bacterial, and anti-virus agent $(1,12-17)$.

Epidemiological evidence has demonstrated that frequent consumption of nuts is beneficial in reducing risk factors for coronary heart disease (CHD). Moreover, researches have indicated that pistachio consumption in individuals with moderate hypercholesterolemia improved blood lipid disorders (17-20). Some of these beneficial effects may be related to the antioxidants naturally present in pistachios, since pistachio consumption has been shown to reduce oxidative stress markers in healthy subjects (10). Recently, pistachio has been used to treat central nervous system diseases because of its beneficial compounds such as antioxidants and phytochemicals and strong anti-inflammatory properties $(21,22)$. Its use has been recommended in Alzheimer's disease and epilepsy (21). Since the pistachio is effective in the treatment of some neurological disorders and is indigenous to Iran, and considering the substantial use of this nut, it is necessary to investigate its effects on cognitive functions of the brain. This study aimed to investigate the effect of the hydroalcoholic extract of the pistachio on avoidance learning in rats.

\section{Material and Methods}

Animal: In the present study, 40 male Wistar rats (200-250 g body weight) were divided into 4 groups of 10 rats. The rats were housed in standard cages with a 12-hour light-dark cycle. The laboratory temperature was set at $23 \pm 2.0$ ${ }^{\circ} \mathrm{C}$. Food and water was available ad libitum.

All experimental procedures were carried out in accordance with the guidelines for the care and use of laboratory animals observed in the Rafsanjan University of Medical Sciences, Iran, and the European Communities Council Directive of 24 November 1986 (86/609/EEC).

Plant material: The pistachio nuts (Akbari Pistachio type) were collected from cultivated plants in Rafsanjan botanical gardens, Iran. The species was identified by a specialist at the Botany Research Division, Valiasr University of Rafsanjan.

Plant extraction: The dried pistachio nuts were powdered, then, $500 \mathrm{~g}$ of powder was added to distilled water and methanol in a ratio of 1 to 1 for 24 hours. This operation was performed in two stages. Then, the mixture was filtered and the solvent was removed through evaporation under reduced pressure at $50{ }^{\circ} \mathrm{C}$ by an incubator apparatus. The extract was reconstituted by dissolving it in dimethyl sulfoxide (DMSO) $2.5 \%$ before use.

Animal groups: The animals were randomly divided into 4 groups of 10 rats. The groups included the vehicle group which received DMSO $2.5 \%$, and 4 treatment groups which received 10,50 , and $100 \mathrm{mg} / \mathrm{kg} /$ day pistachio extract. The DMSO $2.5 \%$ and hydroalcoholic 
extract of the pistachio were administered by gavage for 14 days. All drugs (extract and vehicle) were administered between 8-10 hours in the morning.

Avoidance learning test: Avoidance learning test was performed using the shuttle box. The shuttle box apparatus includes two rooms of relatively the same size $(20 \times 20 \times 30 \mathrm{~cm})$. The guillotine doors in the middle of the separation wall can be manually removed. The walls and floor of one chamber were enclosed with opaque Plexiglas and the walls of the other chamber were dark. The floor of the compartments is composed of stainless steel rods $(3 \mathrm{~mm}$ in diameter and a width of $1 \mathrm{~cm}$ ). In the grid floor of the dark compartment intermittent electric shocks $(50 \mathrm{~Hz}, 3$ seconds, $1.5 \mathrm{~mA}$ intensity) were produced by an isolated stimulator.

\section{Process of avoidance learning test}

1) Adaptation Phase: The adaptation phase was followed by a single trial in which the rats were put into the illuminated compartment and allowed to enter the dark compartment. When the animal entered the next compartment on all 4 paws, the guillotine door was closed and the rat was drawn out from the chamber. The animal was removed from the study, if it did not enter the dark compartment after 300 seconds.

2) Acquisition phase: This stage was performed 1 hour after the adaptation phase. The animal was placed in the illuminated compartment, and after 30 seconds, the guillotine door was opened and the animal was allowed to enter the dark chamber. The entrance latency (step-through latency, STLa) to the dark compartment was recorded. After the animal had placed all 4 paws in the dark compartment, the guillotine door was closed immediately and a single inescapable scrambled foot shock ( $0.2 \mathrm{~mA}, 2$ seconds) was delivered through the grid base. After 20 seconds, the rat was withdrawn from the apparatus and temporarily placed in their home cage. The procedure was repeated until the entrance latency to the dark compartment was more than 300 seconds.

3) Retrieval phase: Each animal was placed in the illuminated compartment 24 hours after the acquisition phase and the door was opened after 5 seconds. The entrance latency to the dark compartment (step-through latency, STLr) and time spent in the dark compartment (TDC) was recorded until a maximum of 300 seconds. No foot shock was delivered when in the retrieval phase. Animals that did not enter the dark chamber during the retrieval phase were allotted a latency of 300 seconds.

4) Statistical Analysis: The statistical analysis was performed using the SPSS software (version 20, SPSS Inc., Chicago, IL, USA). The results of the Kolmogorov-Smirnov test confirmed the normality of the data in all groups (all $\mathrm{P}>$ 0.050). All data are expressed as mean \pm SEM, and P-values smaller than 0.05 were considered to indicate statistical significance. Differences between the groups were determined using oneway ANOVA. All post hoc comparisons were made using Tukey's post hoc test.

\section{Results}

Step-through passive avoidance test was used to assess learning and memory in rats. ANOVA results indicated that oral administration of pistachio extract $(10,50$, and $100 \mathrm{mg} / \mathrm{kg} / \mathrm{day})$ had no significant effect on step-through latency (STLa) in the acquisition phase when compared with the vehicle group $\left(\mathrm{f}_{(3,36)}=0.28, \mathrm{P}=0.800\right)$ (Figure 1).

The comparison of different doses of the extract revealed that animals treated with $100 \mathrm{mg} / \mathrm{kg}$ of the extract had higher STLr time than the DMSO group $(\mathrm{P}=0.016)$ (Figure 2$)$.

In line with STLr, total TDC spent by rats decreased in the extract treated groups compared with the vehicle group $\left(\mathrm{f}_{(3,36)}=4.22, \mathrm{P}=0.010\right)$. In addition, the comparison between different doses of the extract revealed that animals treated 
with $100 \mathrm{mg} / \mathrm{kg}$ of the extract had lower TDC than the DMSO group $(\mathrm{P}=0.006)$ (Figure 3$)$.

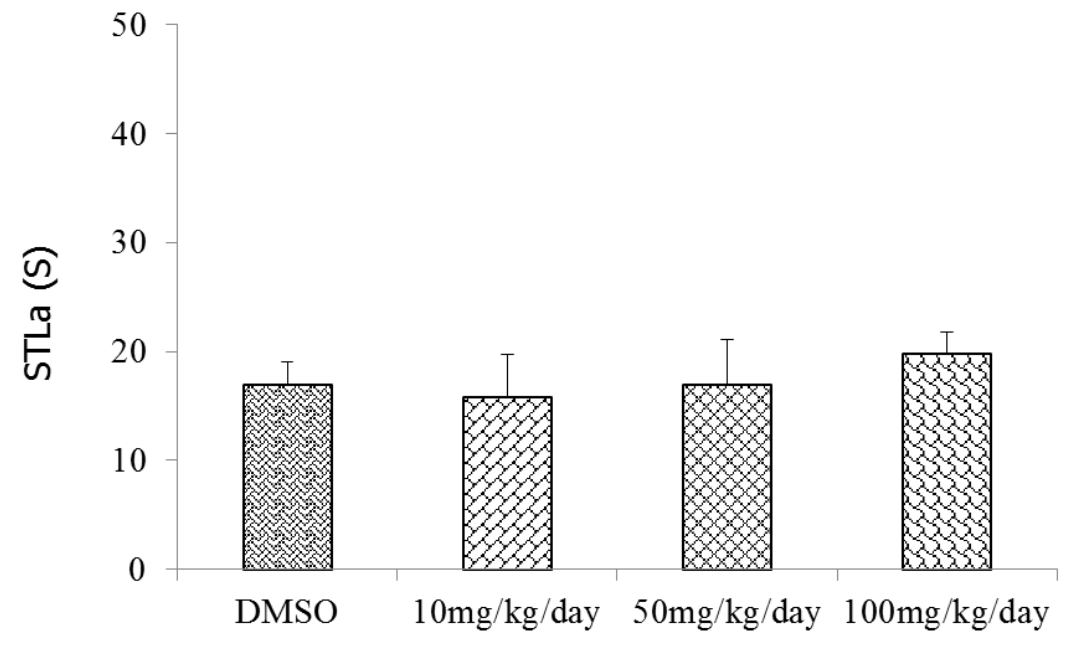

Groups

Figure 1. Step-through latency (STLa) of the experimental groups in the acquisition phase In the retrieval phase, the stepthrough latency (STLr) in rats treated with pistachio extract was significantly higher compared to the vehicle group $\left(f_{(3,36)}\right.$ $=3.48, P=0.020$ ).

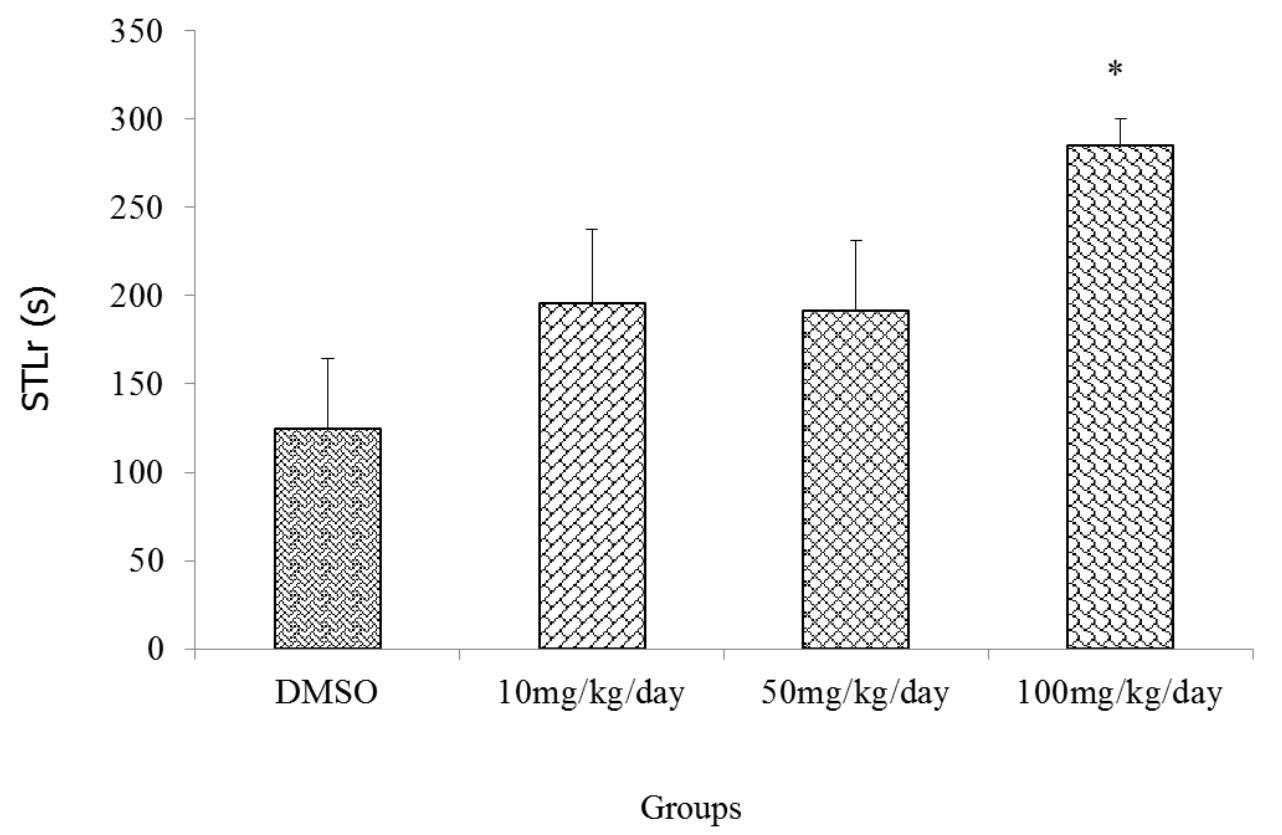

Figure 2. Step-through latency (STLr) of the experimental groups in the retrieval phase

* Significant difference between dimethyl sulfoxide (DMSO) and $100 \mathrm{mg} / \mathrm{kg} /$ day group $(\mathrm{P}=0.016)$. 


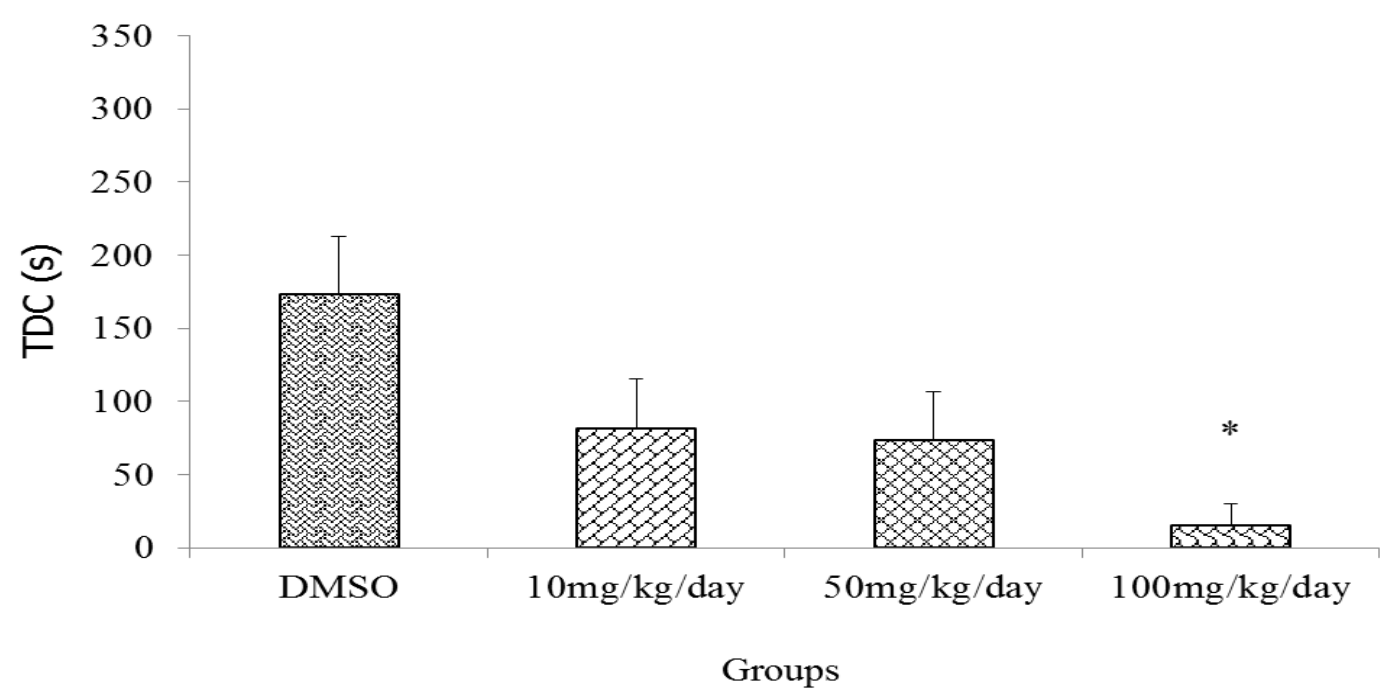

Figure 3. Time spent in the dark compartment by the experimental groups in the retrieval phase * Significant difference between dimethyl sulfoxide (DMSO) and $100 \mathrm{mg} / \mathrm{kg} /$ day group $(\mathrm{P}=0.006)$

\section{Discussion}

In this study, the effects of the hydroalcoholic extract of the pistachio were investigated on avoidance learning in male Wistar rats. The results indicate that treatment of rats with pistachio extract could improve learning and memory.

In traditional Iranian medicine, various species of pistachios have been used as a treatment for various diseases. For example, it was suggested that the kernel of $\mathrm{P}$. vera is a tonic for the heart, liver, stomach, and brain. Fruits of P. atlantica, P. khinjuk, and P. terebinthus were used to treat liver, kidneys, heart, and respiratory system disorders, and their gum for wound healing and treatment of brain and gastrointestinal disorders $(23,24)$. Furthermore, other beneficial effects of pistachios include antiseptic, antimicrobial, antidiabetic, anti-inflammatory, anti-nociceptive, anti-hepatotoxic, and anticancer effects (25).

Because of their beneficial ingredients such as antioxidants, flavonoids, vitamins, and minerals, and strong anti-inflammatory properties, pistachios are used to treat central nervous system diseases such as Alzheimer's disease and epilepsy $(21,22)$. The beneficial effect of the pistachio on the nervous system may be due to its compositions. The impact of some plants on enhancement of memory and relieving of amnesia may be due to polyphenolic antioxidant substances such as flavonoids, vitamin $\mathrm{E}$, and resveratrol (26). Flavonoids are compounds known for their effects on the central nervous system (27). Flavonoids and other polyphenolic compounds inhibit free radicals production and lipid peroxidation. The pistachio extract is rich in natural antioxidants, and thus, can be used as a therapeutic agent for diseases associated with the aging process and free radicals, such as neural degeneration $(28,29)$. Free radicals play an important role in nerve damage caused by stroke and Alzheimer's disease (30). Hence, pistachios may be used as a beneficial factor for the treatment of these diseases and improvement in learning and memory $(21,22,28)$. Various vitamins, particularly vitamins B1, B2, B6, E, and $\mathrm{C}$, in addition to improving physical strength, increase nervous power, and therefore, 
are used for the treatment of central nervous system diseases (31).

Research has shown that vitamin E deficiency in cases such as aging, negatively affects learning and memory (32). Vitamin E, through its antioxidant activity in the hippocampus, inhibits memory loss and enhances learning (33-35). It has also been shown that ascorbic acid has positive effects on learning and memory (36, 37). Ascorbic acid regulates the activity of the glutamate and dopamine systems $(36,37)$. These two neurotransmitters play a major role in learning and memory; therefore, ascorbic acid is effective on learning and memory through these two neurotransmitters and small amounts of ascorbic acid improve learning (37). Since the pistachio contains these vitamins and antioxidant compounds, it can be expected to be effective on the learning and memory processes in animals.

\section{Conclusion}

The results of this study demonstrated that gavage of the hydroalcoholic extract pistachio could improve learning and memory in rats. Further studies on patients with learning and memory deficits are suggested to understand whether this nut could be recommended for humans.

\section{Acknowledgement}

This article was extracted from the thesis prepared by Masumeh Baloochi to fulfill the requirements for her medical degree. The authors acknowledge the Research Deputy of Rafsanjan University of Medical Sciences for the financial support of this research.

Conflict of interest: None declared

\section{References}

1. Sharafzadeh S, Alizadeh O. Some medicinal plants cultivated in Iran. Journal of Applied Pharmaceutical Science 2012; 2(1):134-7.

2. Tohidi M, Khayami M, Nejati V, Meftahizade H. Evaluation of antibacterial activity and wound healing of Pistacia atlantica and Pistacia khinjuk. J Med Plant Res 2011; 5(17):4310-4.

3. Mozaffarian V. Trees and shrubs of Iran. $1^{\text {st }}$ ed. Tehran: Farhang Moaser; 2008. P.1-1452.

4. Kole C. Wild crop relatives: genomic and breeding resources. $1^{\text {st }}$ ed. United States of America: Springer-Verlag Berlin Heidelberg; 2011. P.1-497.

5. Parham M, Heidari S, Khorramirad A, Hozoori M, Hosseinzadeh F, Bakhtyari L, et al. Effects of pistachio nut supplementation on blood glucose in patients with type 2 diabetes: a randomized crossover trial. Rev Diabet Stud 2014; 11(2):1906.

6. Gentile C, Tesoriere L, Butera D, Fazzari M, Monastero M, Allegra M, et al. Antioxidant activity of Sicilian pistachio (Pistacia vera L. var. Bronte) nut extract and its bioactive components. J Agric Food Chem 2007; 55(3):643-8.

7. Tomaino A, Martorana M, Arcoraci $\mathrm{T}$, Monteleone D, Giovinazzo C, Saija A. Antioxidant activity and phenolic profile of pistachio (Pistacia vera L., variety Bronte) seeds and skins. Biochimie 2010; 92(9):1115-22.

8. Ahmad NS, Farman M, Najmi MH, Mian KB, Hasan A. Pharmacological basis for use of Pistacia integerrima leaves in hyperuricemia and gout. J Ethnopharmacol 2008; 117(3):478-82.

9. Daneshrad A, Aynehchi Y. Chemical studies of the oil from pistacia nuts growing wild in Iran. J Am Oil Chem Soc 1980; 57(8):248-9.

10. Edwards K, Kwaw I, Matud J, Kurtz I. Effect of pistachio nuts on serum lipid levels in patients with moderate hypercholesterolemia. J Am Coll Nutr 1999; 18(3):229-32.

11. Dimas K, Hatziantoniou S, Wyche JH, Pantazis P. A mastic gum extract induces suppression of growth of human colorectal tumor xenografts in immunodeficient mice. In Vivo 2009; 23(1):63-8.

12. Demo A, Petrakis C, Kefalas P, Boskou D. Nutrient antioxidants in some herbs and Mediterranean plant leaves. Food Res Int 1998; 31(5):351-4.

13. Pascual-Villalobos MJ, Robledo A. Screening for anti-insect activity in Mediterranean plants. Ind Crops Prod 1998; 8(3):183-94.

14. Souri E, Amin G, Dehmobed-Sharifabadi A, Nazifi A, Farsam H. Antioxidative activity of 
sixty plants from Iran. Iranian Journal of Pharmaceutical Research 2010; 3(1):55-9.

15. Dedoussis GV, Kaliora AC, Psarras S, Chiou A, Mylona A, Papadopoulos NG, et al. Antiatherogenic effect of pistacia lentiscus via GSH restoration and downregulation of CD36 mRNA expression. Atherosclerosis 2004; 174(2):293-303.

16. Hosseinzadeh H, Behravan E, Soleimani MM. Antinociceptive and anti-inflammatory effects of pistacia vera leaf extract in mice. Iran J Pharm Res 2011; 10(4):821-8.

17. Hamdan I, Afifi F. Studies on the in vitro and in vivo hypoglycemic activities of some medicinal plants used in treatment of diabetes in Jordanian traditional medicine. J Ethnopharmacol 2004; 93(1):117-21.

18. Due A, Larsen TM, Mu H, Hermansen K, Stender S, Astrup A. Comparison of 3 ad libitum diets for weight-loss maintenance, risk of cardiovascular disease, and diabetes: a 6-mo randomized, controlled trial. Am J Clin Nutr 2008; 88(5):1232-41.

19. Gebauer SK, West SG, Kay CD, Alaupovic P, Bagshaw D, Kris-Etherton PM. Effects of pistachios on cardiovascular disease risk factors and potential mechanisms of action: a doseresponse study. Am J Clin Nutr 2008; 88(3):6519.

20. Hu FB, Stampfer MJ, Manson JE, Rimm EB, Colditz GA, Rosner BA, et al. Frequent nut consumption and risk of coronary heart disease in women: prospective cohort study. BMJ 1998; 317(7169):1341-5.

21. Abdollahi Fard M, Shojaii A. Efficacy of Iranian traditional medicine in the treatment of epilepsy. Biomed Res Int 2013; 2013:692751. doi: 10.1155/2013/692751. Epub 2013 Jul 7.

22. Ahmad NS, Waheed A, Farman M, Qayyum A. Analgesic and anti-inflammatory effects of Pistacia integerrima extracts in mice. $\mathrm{J}$ Ethnopharmacol 2010; 129(2):250-3.

23. Kashaninejad M, Mortazavi A, Safekordi A, Tabil LG. Some physical properties of pistachio (pistacia vera L.) nut and its kernel. J Food Eng 2006; 72(1):30-8.

24. Alma MH, Nitz S, Kollmannsberger H, Digrak M, Efe FT, Yilmaz N. Chemical composition and antimicrobial activity of the essential oils from the gum of Turkish pistachio (Pistacia vera L.). J Agric Food Chem 2004; 52(12):3911-4.

25. Bozorgi M, Memariani Z, Mobli M, Salehi Surmaghi MH, Shams-Ardekani MR, Rahimi R. Five Pistacia species (P. vera, P. atlantica, P. terebinthus, P. khinjuk, and P. lentiscus): a review of their traditional uses, phytochemistry, and pharmacology. Scientific World Journal 2013; 2013:219815. doi: 10.1155/2013/219815. eCollection 2013.

26. Emami M, Hosseini A, Saeedi A, Golbidi D, Reisi P, Alaei H. Effect of red grape juice on learning and passive avoidance memory in rats. Journal of Isfahan Medical school 2010; 28(104):1-8.

27. Shivakumar SI, Suresh HM, Hallikeri CS, Hatapakki BC, Handiganur JS, Sankh K, et al. Anticonvulsant effect of Cyperus rotundus linn rhizomes in rats. Journal of Natural Remedies 2009; 9(2):192-6.

28. Nagulendran KR, Velavan S, Mahesh R, Begum VH. In vitro antioxidant activity and total polyphenolic content of Cyperus rotundus rhizomes. J Chem 2007; 4(3):440-9.

29. Kilani-Jaziri S, Neffati A, Limem I, Boubaker J, Skandrani I, Sghair MB, et al. Relationship correlation of antioxidant and antiproliferative capacity of Cyperus rotundus products towards K562 erythroleukemia cells. Chem Biol Interact 2009; 181(1):85-94.

30. Tayarani-Najaran Z, Sadeghnia HR, Asghari M, Mousavi SH. Neuroprotective effect of Nigella sativa hydro alcoholic extract on serum/glucose deprivation induced PC12 cells death. Physiology and Pharmacology 2009; 13(3):263-70.

31. West SG, Gebauer SK, Kay CD, Bagshaw DM, Savastano DM, Diefenbach C, et al. Diets containing pistachios reduce systolic blood pressure and peripheral vascular responses to stress in adults with dyslipidemia. Hypertension 2012; 60(1):58-63.

32. Fukui K, Onodera K, Shinkai T, Suzuki S, Urano $\mathrm{S}$. Impairment of learning and memory in rats caused by oxidative stress and aging, and changes in antioxidative defense systems. Ann N Y Acad Sci 2001; 928:168-75.

33. Alzoubi KH, Khabour OF, Rashid BA, Damaj IM, Salah HA. The neuroprotective effect of vitamin $\mathrm{E}$ on chronic sleep deprivation-induced memory impairment: the role of oxidative stress. Behav Brain Res 2012; 226(1):205-10.

34. Tagliari B, Scherer EB, Machado FR, Ferreira AG, Dalmaz C, Wyse ATS. Antioxidants prevent memory deficits provoked by chronic variable stress in rats. Neurochem Res 2011; 36(12):237380.

35. Kim EM, Elliot J, Hobson P, O'Hare E. Effects of intrahippocampal NAC 61-95 injections on memory in the rat and attenuation with vitamin $\mathrm{E}$. 
Prog Neuro-Psychopharmacol Biol Psychiatry 2009; 33(6):945-51.

36. Rebec GV, Pierce RC. A vitamin as neuromodulator: ascorbate release into the extracellular fluid of the brain regulates dopaminergic and glutamatergic transmission. Prog Neurobiol 1994; 43(6):537-65.
37. Esmaili MH, Doodangeh E, Sharifi M. The effect of ascorbic acid on spatial learning. The Journal of Qazvin University of Medical Sciences 2003; 6(4):3-8. 